\title{
Gendered specialities during medical education: a literature review
}

\author{
Margret Alers • Lotte van Leerdam • \\ Patrick Dielissen • Antoine Lagro-Janssen
}

Published online: 1 July 2014

(C) The Author(s) 2014. This article is published with open access at Springerlink.com

\begin{abstract}
The careers of male and female physicians indicate gender differences, whereas in medical education a feminization is occurring. Our review aims to specify genderrelated speciality preferences during medical education. A literature search on gender differences in medical students' speciality preferences was conducted in PubMed, Eric, Embase and Social Abstracts, and reference lists from January 2000 to June 2013. Study quality was assessed by critical appraisal. Our search yielded 741 hits and included 14, mostly cross-sectional, studies originating from various countries. No cohort studies were found. Throughout medical education, surgery is predominantly preferred by men and gynaecology, paediatrics and general practice by women. Internal medicine was pursued by both genders. The extent of genderspecific speciality preferences seemed related to the male-to-female ratio in the study population. When a population contained more male students gynaecology seemed even more preferred by women, while in a more feminine population, men more highly preferred surgery. Internationally, throughout medical education, genderrelated speciality preferences are apparent. The extent might be influenced by the male-to-female ratio of a study population. Further research of the role of gender in career considerations of medical students on the future workforce is necessary.
\end{abstract}

Keywords Medical students - Gender differences - Speciality preference

M. Alers $(\bowtie) \cdot$ L. van Leerdam $\cdot$ P. Dielissen · A. Lagro-Janssen

Unit Gender and Women's Health, Department of Primary and Community Care, Radboud University Medical Centre, ELG-117, PO Box 9101, 6500 HB Nijmegen, the Netherlands email: Margret.Alers@radboudumc.nl 


\section{Introduction}

The increase in the proportion of women in medical schools suggests equal educational and professional opportunities [1, 2]. Interestingly, in the current medical profession the distribution of physicians across some specialities does not increase proportionally. There is an unbalanced horizontal segregation, exemplifying a vast majority of men surgeons and women gynaecologists [3-6]. Also disproportionately few women occupy senior positions in medicine, this is called vertical segregation $[6,7]$. Gender seems to affect medical career choices.

Gender-related differences in medical career choices can be explained by several factors. Firstly, the cultural background might be an intrinsic influence on speciality choices. For example, women anticipate having a family and are thus probably more likely to choose a caring profession [8,9]. Secondly, different choices in medical careers might be caused by gender bias. This might be the case in unequal treatment in educational opportunities and expectations or when negative experiences (gender discrimination or sexual harassment) in speciality orientation occur [5, 6]. On the other hand, some studies suggest that social behaviour of men and women is equal and not constraining. They see gender as one of multiple identities, that should be seen in context and the influence of gender should not be overrated [10]. Even though gender-related priorities of medical students do not appear of practical importance regarding motivation or skills, horizontal and vertical gender differences in medical careers have been indicated $[6,11]$. Therefore, it is important to look at how women and men develop their career considerations during medical training.

At the start, both sexes receive equal access to medical education. During training, several factors lead to a particular medical speciality choice including gender [12]. In this study, we explore what is already known about gender-related speciality preferences during medical education. The aim is to [1] explore the extent of differences between speciality preferences of women and men medical students during the whole medical study including clerkships and [2] how women and men modify or remain with their speciality preferences.

\section{Method}

\section{Search}

A search strategy was formulated in PubMed and adapted for use in the databases of Eric, Embase and Sociological Abstracts ("Appendix 1"). A skilled librarian verified our search. Other relevant studies were collected by a hand search for references in all included articles (snowball method). No other additional searches were performed, e.g. via Internet search.

Because of diverse international denomination, medical students during the whole medical study were searched as: medical students, medical education and medical school. In the Netherlands a Bachelor and Master Degree structure is applicable [13]. At the European level, this structure has been introduced in medical curricula on a limited scale [14]. Terms for a bachelor degree were further defined as bachelor, 
undergraduate(s) and pre-graduate(s). Students before completion of their master degree programme were included using the keywords: master, internship, clerkship, house officer, foundation year, senior year and clinical rotation. Not included were graduates from medical school or medical physician, resident, registrar, senior house officer, fellowship, clinical attachment. For this review, we also used a gender filter, locating sex-specific evidence on clinical questions which has been adapted to PubMed [15]. The gender filter included keywords as gender, sex and differences. The primary outcome of studies included in our review was speciality preferences, also searched for as career choice.

\section{Inclusion and exclusion criteria}

We searched the databases on articles published between 2000 and June 2013. The search included full-text studies of original research written in Dutch, English, French or German and published in peer-reviewed journals.

We included all studies meeting the following criteria: (1) involving medical students up till graduation, (2) assessing and reporting gender differences, and (3) evaluating speciality preferences for men and women. We excluded studies that (1) involved students or physicians in postgraduate training. As a result, general studies on career preferences were mostly not suitable. We also excluded studies (2) investigating the preference for a particular speciality or evaluating speciality preferences either for women or men solely.

Selection and quality assessment

All review steps were performed by two reviewers independently (MTA, LL). We selected articles based on titles and abstracts. If agreement could not be reached between the reviewers on basis of title and abstract, the full-text article was assessed for eligibility.

Most selected articles concerned observational cross-sectional studies. There are few tools in the literature available to assess quality in observational studies [16] and only one of them had some interface with the selected articles in our review [17]. We assessed the quality of these quantitative observational cross-sectional studies using relevant critical appraisal criteria from other studies and based on Cochrane's criteria [17-21]. Components included in our critical appraisal were [1] an evaluation of the appropriateness of the study design for the research question [2], a careful assessment of the key methodological features of the design [3], the appropriateness of statistical analysis, and [4] the legitimacy of conclusions ("Appendix 2").

We included a component rating and a global rating for each article. Criteria were checked whether satisfied with a yes, can't tell or no. When satisfied, 1 point was assigned. A total number of 10 points could be obtained for the individual criteria and these were proportionally distributed as [1-3] weak [4-6], moderate, and [7-10] strong. Both reviewers assessed reliability of the checklist in a pilot phase before applying it to all the selected studies. Ratings from the two researchers were averaged and studies with a quality score of seven points or higher were included in this review. Cohen's Kappa was calculated of the reviewers' applicability judgment to 
determine inter-rater reliability (good if $>0.8$, poor if $<0.20)$ revealing a score of 0.87 .

\section{Data extraction}

We collected all possible specialities and compared main specialities across the studies between male and female students at the beginning and the end of their education. We described gender differences in speciality preferences for surgery, gynaecology including obstetrics, paediatrics, internal medicine and general practice. Anaesthesiology, dermatology, emergency medicine, ophthalmology, orthopaedics, psychiatry, radiology and other specialities were only described if of interest because these specialities are generally not preferred by large proportions of undergraduate medical students. When processing the results, we used the term maleto-female ratio to indicate the proportion of the number of male versus female students in the population. If there were more male students we named this 'maledominated', while a study population with predominately female students was described as 'female-dominated'.

\section{Results}

Figure 1 shows a flow diagram of the results of the selection process. We identified 741 articles of which 64 met our inclusion criteria. Most retrieved studies were excluded on the basis of title and abstract. After reviewing the full-text article we excluded 49 articles, leaving 15 articles for quality assessment. Quality assessment was not supportive for one study [22], thus 14 articles remained for data extraction [23-36] (Table 1).

\section{Specification studies}

All included studies had a cross-sectional design and therefore could provide an answer to our first research question. Our search yielded no cohort studies which could draw conclusions on development in preferences. The participation rate of students in all included studies was $65 \%$ or higher. The number of participants per study varied considerably from 38 to 4,291 female students and from 70 to 6,308 male students.

We included five studies from Europe [25, 26, 28, 32, 36], three studies from the United States [24, 29, 31], one study from Africa [34], four studies from the MiddleEast [23, 30, 33, 35] and one study from Asia [27].

Seven studies evaluated students' speciality preferences only once $[23,25,26,28$, $29,32,36]$, five studies assessed speciality preferences twice [27, 31, 33-35] and two studies assessed students' speciality preferences at three moments [24, 30].

Six studies reported gender differences at the start [24, 28-31, 36], two studies evaluated halfway medical education $[24,30]$, another six studies found evidence at the end $[23,25,26,30-32]$ and four studies gave an indication during the whole medical study [27, 33-35]. 


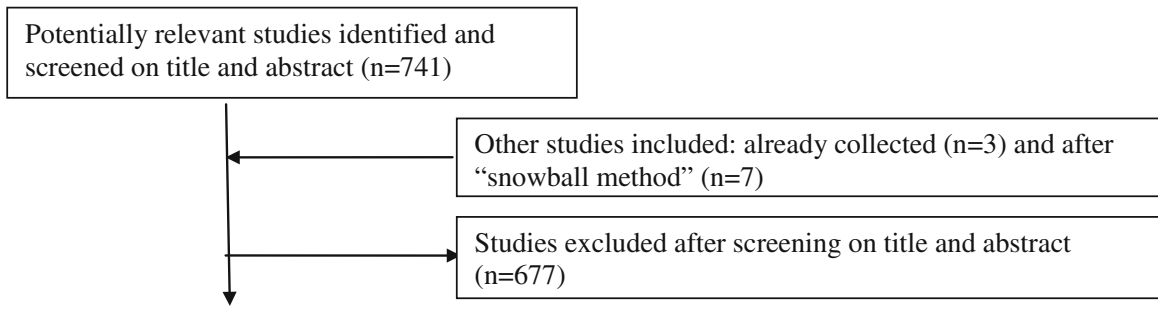

Potentially relevant studies identified and screened on full text $(n=64)$

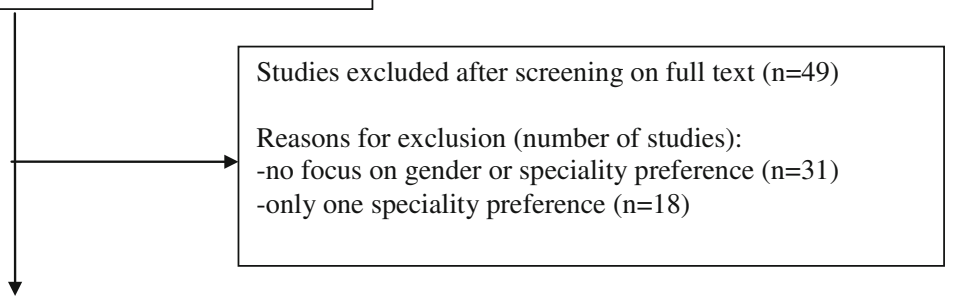

Studies included for quality assessment $(\mathrm{n}=15)$

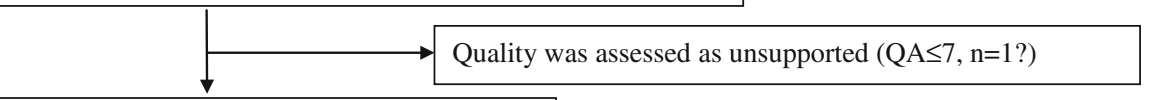

Studies included $(\mathrm{n}=14)$

Fig. 1 Flow chart of selection procedure

Specialities more preferred by women

At the start of their medical education, women were especially interested in gynaecology and paediatrics. A preference for gynaecology was mentioned among 4-18\% of female students compared with $0-2 \%$ of male students, for paediatrics this was 10-21 versus 2-9\% [24, 28-31, 36]. Women also opted for general practice more often than men (F 2-15\% vs. M 0-10\%) [24, 28-31, 36].

Halfway through their medical education, women showed a persistent interest in gynaecology (F $21 \%$ vs. M $0 \%$ ), paediatrics (F $11 \%$ vs. M $7 \%$ ) and general practice (F $4 \%$ vs. M $1 \%$ ) [24, 30].

In addition, at the end of their medical education women continued to prefer a career in gynaecology (F 3-28\%, M 1-5\%), paediatrics (F 7-28 \%, M 1-16 \%) and general practice (F 0-21 \% vs. M 2-17\%) [23, 25, 26, 30-32]. Two studies indicated the opposite; namely, that more male students chose paediatrics [23] or general practice [30] in comparison with female students. Studies following speciality preference throughout the medical education also found women mostly pursued a career in gynaecology (F 5-26\%, M 0-4 \%) and paediatrics (F 6-24 \%, M 3-7 \%) $[27,35]$, though in one study more male students were interested in gynaecology (F $10 \%$, M $13 \%$ ) [34]. 


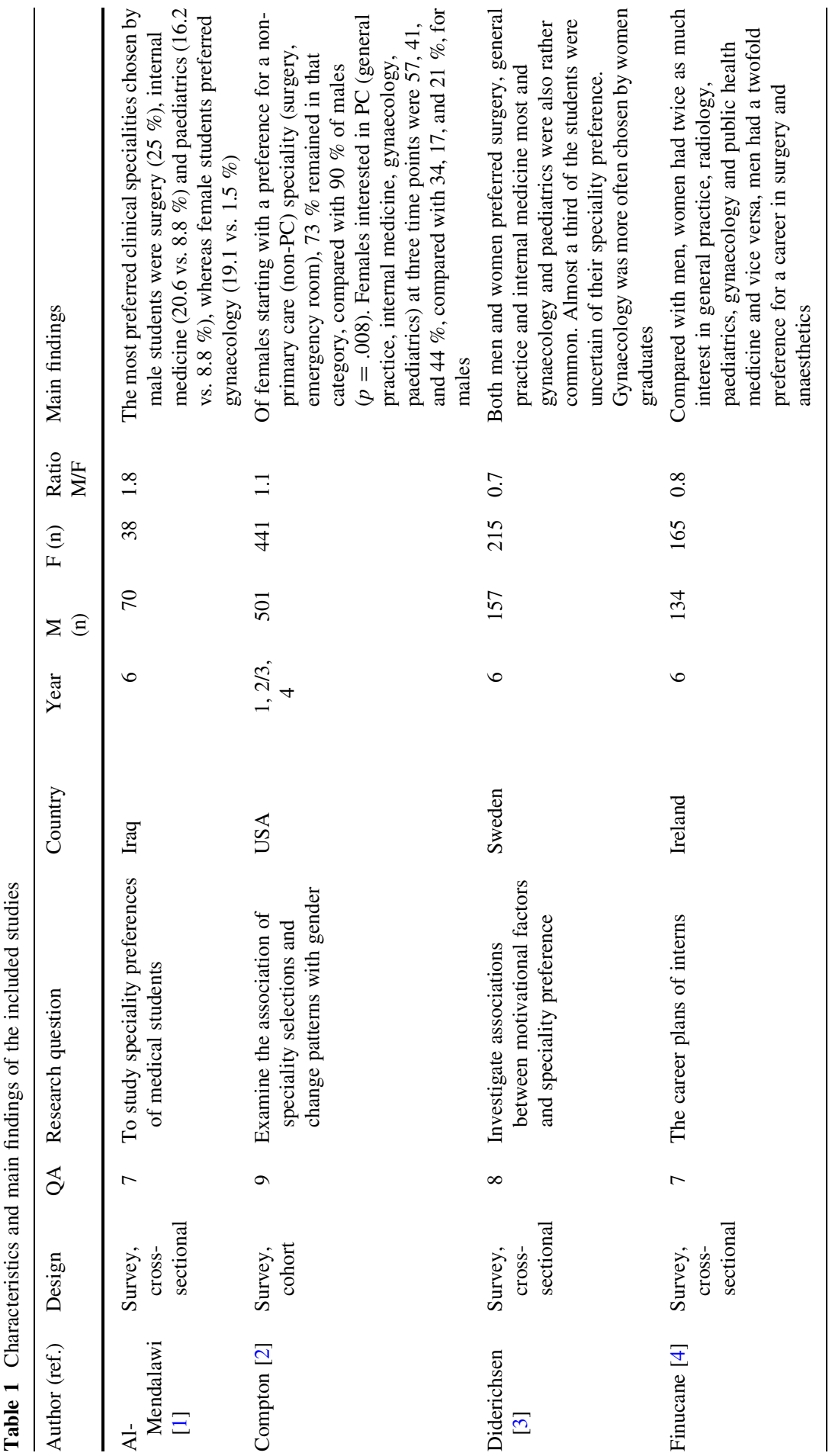




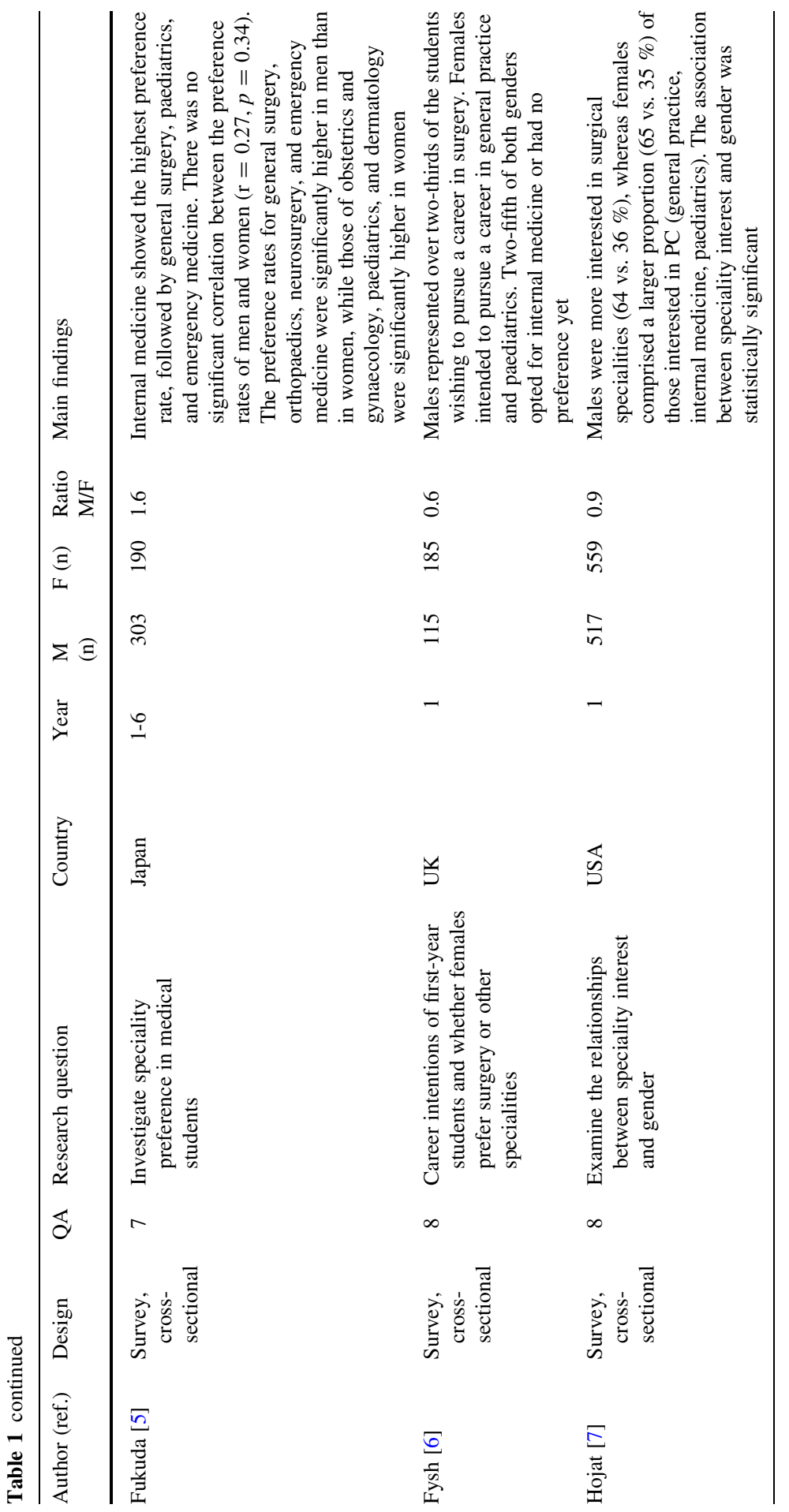




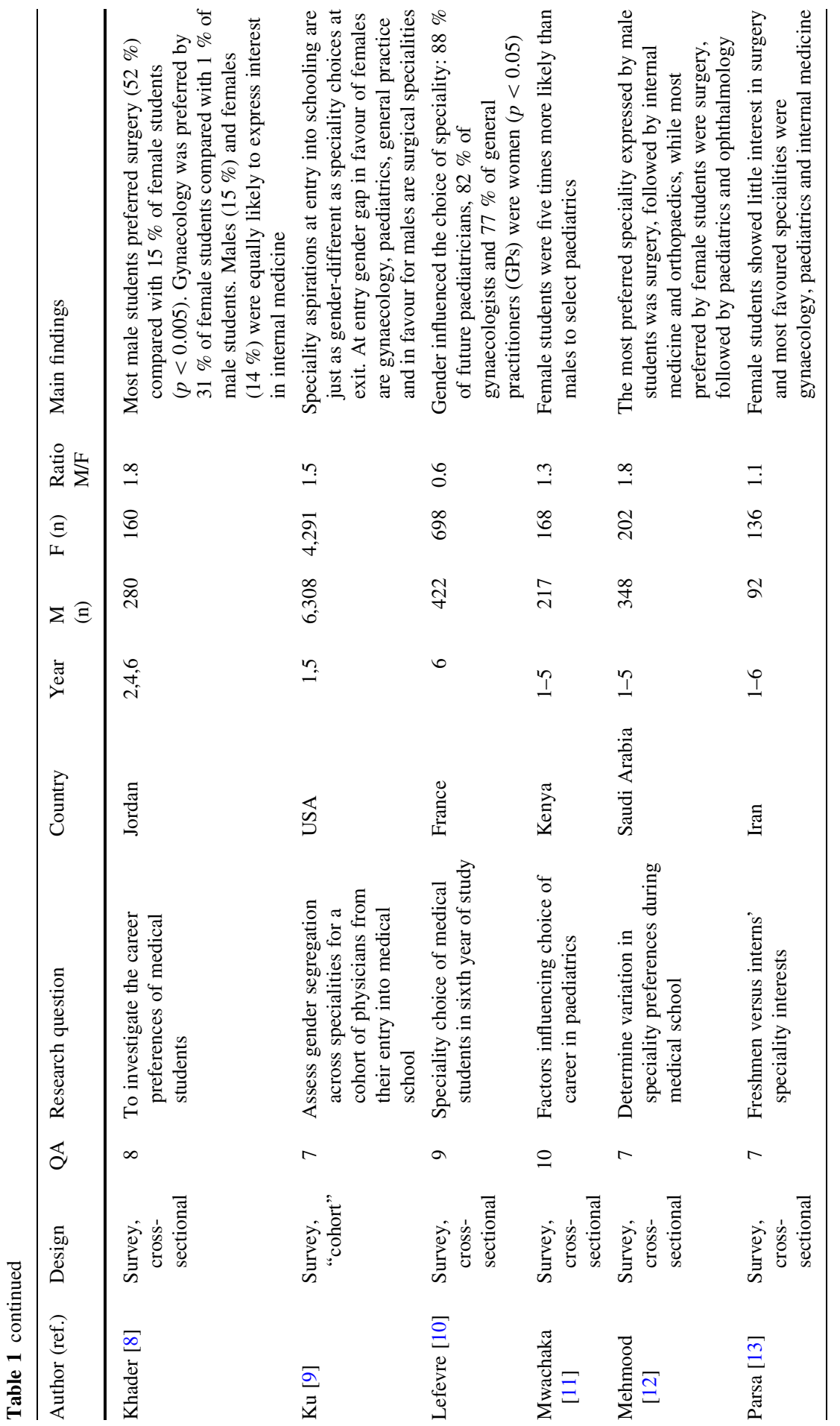




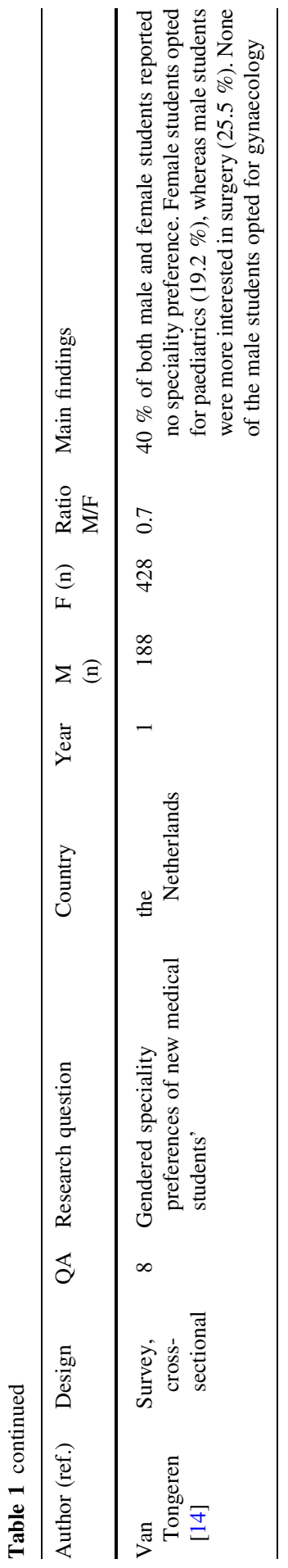


Specialities more preferred by men

In five studies, surgery was the most frequently preferred speciality among men at the start of their medical education, but women showed an interest in surgery as well (F 10-25\% vs. M 39-64 \%) [28-31, 36]. The interest of male students for surgery as speciality remained (F $9 \%$ vs. M $55 \%$ ) [30]. One study from Sweden reported that an equal amount of women and men opted for surgery (F $17 \%$ vs. M $23 \%$ ) [25].

By the end of medical education surgery was still the first choice of men (F 0-12 \% vs. M 15-34 \%) [23, 26, 30-32]. Several studies indicate that throughout medical education especially male students wished to pursue a career in surgery (F 10-17 \% vs. M 26-35 \%) [27, 33-35].

At the start, orthopaedics was also slightly more popular to men (F $6 \%$ vs. M $8 \%$ ) [30, 33]. One study confirmed this midway (F $0 \%$ vs. M $5 \%$ ), one at the end of medical education (F $0 \%$ vs. M $13 \%$ ) [30]. Two studies confirmed men's continuous interest in orthopaedics (F $2 \%$ vs. M $7 \%$ ) [27, 33].

Specialities preferred by both women and men

In three studies, at the start male and female medical students showed an equal interest in internal medicine (F 6-24\% vs. M 6-24\%) [28, 31, 36]. In one study male students were slightly more interested (F $3 \%$ vs. M $8 \%$ ) [30]. Midway, one study confirmed an ongoing mutual interest in internal medicine (F $26 \%$ vs. M $21 \%$ ) [30]. At the end of medical education internal medicine remained the largest equally chosen speciality (F 8-20\% vs. M 9-21\%) [25, 30, 31]. Yet, one study indicated it as a female speciality (F $14 \%$ vs. M $8 \%$ ) [32], and one as a male speciality (F $9 \%$ vs. M $21 \%$ ) [23]. In studies throughout the course, internal medicine remained a speciality preference for both male and female students (F $7 \%$ vs. M 7-10\%) [27, 33-35].

No speciality preference

There were no gender differences in students who had no speciality preference at the start (F 1-41\% vs. M 1-39\%) [28, 31, 36] or at the end of the medical curriculum (F $1-41 \%$ vs. M 1-39\%) $[25,26,31]$. One study mentioned that men more often had no preference than women (F $15 \%$ vs. M $23 \%$ ) [33].

Influence male-to-female ratio on speciality preferences

In most studies with more male students than female students, i.e. 'male-dominated', women to a greater extent preferred gynaecology [23, 27, 30, 31, 33], whereas in a study population with predominately female students, 'female-dominated', still substantially more women chose gynaecology but to a lesser extent [26, 28, 32, 35, 36]. This tendency was also seen in paediatrics [26-28, 30-36] and general practice [23, 26-28, 31, 32, 34-36]. 
The opposite was seen in studies with a high male-to-female ratio, 'maledominated', where substantially more men preferred surgery [23, 27, 30, 31, 33]. In 'female-dominated' study populations, proportionally a larger number of men opted for surgery [26, 28, 32, 35, 36].

There was no influence of the male-to-female ratio in internal medicine speciality preferences [28, 30-36].

\section{Discussion}

We found that specific gender-related speciality preferences are present in the core choices of medical students from the beginning till completion of training, irrespective of nationality or country studied. In particular we saw this in surgery, a speciality highly attractive to men as well as in gynaecology, paediatrics and general practice, specialities which were mostly preferred by women. Internal medicine has an equal attraction to both women and men.

Medical students of both genders are potentially interested in various specialities. Female students are as likely as male students to start their career prospect in surgery but this preference decreases at the end of training, possibly due to heavy workload and a desire to have children [7, 28, 37]. The initial and final speciality preferences of men in our review seem more consistent than those of women [7]. Our results show gender differences in entering specialities at the start of medical careers.

It is challenging to compare study results of so many different countries and cultures. Discrepancies in the gender proportions selecting a speciality may also relate to the country of the study. The cultural background of each country should be taken into account to explain results. Differences in origins of studies might have societal implications. In the included papers, either women or men had the majority in a given speciality preference. In our mostly cross-sectional data it seemed that an unbalanced male-to-female ratio was associated with an even more disproportional selection of already gendered specialities. As such, the extent of gender differences in speciality preferences may relate to the male-to-female ratio in the study population. To determine the influence of the male-to-female ratio in a study population on speciality preferences, more research is needed. Possibly a metaanalysis on (preferably) cohort data in either male 'dominated' or female 'dominated' study populations could be helpful.

Strengths and limitations

Strong points in our literature review are the reproducible and international search strategies with which we found sufficient studies of quality to answer our first research question. However, the number of articles found for inclusion may be a limitation, foremost in our finding on the influence of male-to-female ratio in a study population on speciality preferences. As the search only yielded English-language publications, publication bias could not be ruled out. Most studies were conducted at one university and therefore it might not have been representative of all medical students in that country. And although we critically appraised our studies, we might 
have paid too little attention to geographical distribution of the studies. Furthermore, our rating system for quality assessment could have produced other lists of articles than with other criteria or other weights.

Interpretation and implications of findings

The increasing number of female students ensures a balance shift between the sexes in the medical profession and will weigh the importance of genderdifferences in speciality preferences. Specialities such as gynaecology will be able to provide women patients with even more women gynaecologists. Therefore, it may be not necessary for faculty to reconsider access in single disciplines. However, male and female physicians are equally competent. Gender mainstreaming, which represents the process that brings gender issues from marginal into the core business of an organization, will offer institutions the opportunity to integrate a gender perspective into all phases of its programme cycle [38]. If the male-to-female ratio in specialities is unbalanced, possibly no new role models will be found [39].

Most of the studies call for better career advice by raising awareness about specialities earlier in education or for flexible work and training structures that allow work-life balance [7, 24, 27, 28, 30, 32, 34]. Medical education should include the choice of speciality from an early stage, so a future doctor, woman or man, can have an informed speciality choice on content. We should give more attention to how medical students come to their speciality preferences in order to anticipate how medical education can guide them.

We propose that policy makers take responsibility in matters of gender equality and gender equity when it comes to speciality distribution, instead of waiting till there is an intrinsic change in society in which this normal value is adopted. Reducing gender bias during studies adds value to medical training.

\section{Conclusion}

We note that throughout undergraduate training in various countries some speciality preferences are specifically elected by women or men. Surgery is predominantly preferred by men and gynaecology, paediatrics and general practice by women. The extent of gendered speciality preferences seems related to the male-to-female-ratio in the study population.

Female or male students' career choice seems to be a spontaneous or natural processes in medicine and our findings show that gendered speciality preferences are present throughout medical education. Given the current feminization it is important to pay attention to gender-related speciality preferences.

Acknowledgments The authors are most grateful to Elmie Peters, medical librarian, for her help with the database searches. 
Open Access This article is distributed under the terms of the Creative Commons Attribution License which permits any use, distribution, and reproduction in any medium, provided the original author(s) and the source are credited.

\section{Appendix 1: Search strategies}

PubMed (includes Medline) ((( “"students, medical”[MeSH Terms] OR medical students OR "education, medical" [MeSH Terms] OR medical education OR "schools. medical" [MeSH Terms] OR medical school)) AND ("Education. Medical. Undergraduate"[Mesh] OR "Young Adult"[Mesh] OR ("pre"[tiab] AND graduate*[tiab]) OR pregraduat* OR undergraduate* OR bachelor* OR master* OR internship and residency[MeSH Terms] OR internship OR clerkship OR house officer* OR foundation year* OR senior year* OR clinical rotation*)) AND ("gender identity" [MeSH Terms] OR gender OR "sex characteristics" [MeSH Terms] OR "sex differentiation" [MeSH Terms] OR sex differences OR sex differentiation OR "sex factors" [MeSH Terms] OR sex factors OR sex stereotypes OR ("equal" AND "opportunities"))) AND ("specialization" [MeSH Terms] OR specialization* OR "choice behavior" [MeSH Terms] OR choice* OR prefer* OR career*) AND (English[lang] OR French[lang] OR German[lang] OR Dutch[lang]) AND “2000/ 01/01”[PDAT] : “2013/06/10”[PDAT].

Embase. Eric (OvidSP) ((medical student or medical students or medical education or medical school).mp. or medical student/or exp Medical Education/or undergraduate*.mp.) and (gender.mp. or "equal opportunities (jobs)"/or sex role/or sex stereotypes/) and (specialization or career choice or prefer).mp limit to (dutch or english or french or german) and peer reviewed and yr = "2000-Current 2013".

Sociological abstract (CSA) all(((medical AND (students OR student OR education OR school OR schools)) OR (undergraduate*) OR (("medical students" OR "medical schools"))) AND ((gender) OR (gender difference*) OR (("sex differences" OR "sex stereotypes" OR "sexual inequality"))) AND (((speciality OR career) AND (choice OR preference)) OR (specialization) OR (("specialization" OR "occupational choice")))) AND peer(yes) AND la.exact("English" OR "Dutch" OR "French" OR “German") AND pd(20000101-20130610).

\section{Appendix 2: Checklist of quantitative observational cross-sectional studies}

When critically appraising a research article we tried to find answers to the following questions: 
1 With regard to study design (three points):

Was the study aim and research question or hypothesis clear?

Was the motive or reason for the study stated?

Was the study design appropriate for the research question?

2 With regard to the data collection (four points):

Was the study sample clearly defined? In case of a sample, was the sample representative of the population?

Is there an acceptable response rate (60\% or above)?

Are the methods of data collection appropriate and explicitly described? E.g. consider whether (a) the variables were clearly defined and accurately measured and (b) measurements are justified and appropriate for answering the research question

Did the study methods address the most important potential sources of bias? E.g. consider

(a) selection bias ( $=$ an error in choosing the individuals or groups to take part in research) or

(b) reporting bias (being more trusting of expected or desirable results, while under-reporting unexpected or undesirable experimental results)?

3 Statistical analysis (two points)

Were the statistical analyses performed correctly?

Is there a description of the statistical analysis with clarity of approach and credibility of the analysis: e.g. interpretations made by the researcher, how themes were derived?

4 Conclusions (one point)

Do the data justify the conclusions?

\section{References}

1. Boulis A, Jacobs J, Veloski JJ. Gender segregation by speciality during medical school. Acad Med. 2001;76(10 Suppl):S65-7.

2. Bickel J. Gender equity in undergraduate medical education: a status report. J Womens Health Gend Based Med. 2001;10(3):261-70.

3. Lambert TW, Goldacre MJ, Turner G. Career choices of United Kingdom medical graduates of 2002: questionnaire survey. Med Educ. 2006;40(6):514-21.

4. Freeman B. Special considerations for woman. In: Compagnies MGH, editor. The ultimate guide to choosing medical speciality special 2004.

5. Riska E, editor. Gender in medical education. 2008; Finland.

6. Kilminster S, Downes J, Gough B, Murdoch-Eaton D, Roberts T. Women in medicine-is there a problem? A literature review of the changing gender composition, structures and occupational cultures in medicine. Med Educ. 2007;41(1):39-49.

7. Drinkwater J, Tully MP, Dornan T. The effect of gender on medical students' aspirations: a qualitative study. Med Educ. 2008;42(4):420-6.

8. Buddeberg-Fischer B, Stamm M, Buddeberg C, et al. The impact of gender and parenthood on physicians' careers-professional and personal situation seven years after graduation. BMC Health Serv Res. 2010;10:40.

9. Cancian FM, Oliker SJ. Caring and gender. In: Littlefield R, editor. 2000.

10. Tsouroufli M, Rees C, Monrouxe L, Sundaram V. Gender, identities and intersectionality in medical education research. Med Educ. 2011;45:213-6.

11. Hyde JS. The gender similarities hypothesis. Am Psychol. 2005;60(6):581-92.

12. Ridell ST, Tett L. Gender balance in teaching debate: tensions between gender theory and equality policy. IJIE. 2009. 
13. Laan R, Leunissen R, Van Herwaarden C. The 2009 framework for undergraduate medical education in the Netherlands. Ned Tijdschr Geneeskd. 2010;29, nr. 1(-):10-5.

14. Patricio M, den Engelsen C, Tseng D, Ten Cate O. Implementation of the Bologna two-cycle system in medical education: where do we stand in 2007? — results of an AMEE-MEDINE survey. Med Teach. 2008;30(6):597-605.

15. Moerman CJ, Deurenberg R, Haafkens JA. Locating sex-specific evidence on clinical questions in MEDLINE: a search filter for use on OvidSP. BMC Med Res Methodol. 2009;9:25.

16. Sanderson S, Tatt ID, Higgins JP. Tools for assessing quality and susceptibility to bias in observational studies in epidemiology: a systematic review and annotated bibliography. Int $\mathrm{J}$ Epidemiol. 2007;36(3):666-76.

17. Weightman AL, Mann MK, Sander L, Turley RL. Questions to assist with the critical appraisal of an observational study eg cohort, case-control, crosssectional. A systematic approach to identifying the evidence, Project methodology 5. Cardiff: Information Services UWCM, January 2004 http://hebw.uwcm.ac.uk/projectmethod/Project\%20Methodology\%205.pdf.

18. Cochrane. Handbook Systematic Reviews of Health Promotion and Public Health intervention; Unit Eight: Principles of Critical Appraisal. Deakin University and the Australian Department of Health and Aging, 2005.

19. Young JM, Solomon MJ. How to critically appraise an article. Nat Clin Pract Gastroenterol Hepatol. 2009;6(2):82-91.

20. Khan KS, Kunz R, Kleijnen J, Antes G. Five steps to conducting a systematic review. Study quality assessment. J R Soc Med. 2003;96(3):118-21.

21. Pace R, Pluye P, Bartlett G, et al. Testing the reliability and efficiency of the pilot Mixed Methods Appraisal Tool (MMAT) for systematic mixed studies review. Int J Nurs Stud. 2012;49(1):47-53.

22. Al-Nuaimi Y, McGrouther G, Bayat A. Modernising medical careers and factors influencing career choices of medical students. Br J Hosp Med. 2008;69(3):163-6.

23. Al-Mendalawi MD. Speciality preferences of Iraqi medical students. Clin Teach. 2010;7(3):175-9.

24. Compton MT, Frank E, Elon L, Carrera J. Changes in U.S. medical students' speciality interests over the course of medical school. J Gen Intern Med. 2008;23(7):1095-100.

25. Diderichsen S, Johansson EE, Verdonk P, Lagro-Janssen T, Hamberg K. Few gender differences in speciality preferences and motivational factors: a cross-sectional Swedish study on last-year medical students. BMC Med Educ. 2013;13:39.

26. Finucane P, O'Dowd T. The career plans of Irish interns: results of a national survey. Ir Med J. 2004;97(5):149.

27. Fukuda Y, Harada T. Gender differences in speciality preference and mismatch with real needs in Japanese medical students. BMC Med Educ. 2010;10:15.

28. Fysh TH, Thomas G, Ellis H. Who wants to be a surgeon? A study of 300 first year medical students. BMC Med Educ. 2007;19(7):2.

29. Hojat M, Zuckerman M. Personality and speciality interest in medical students. Med Teach. 2008;30(4):400-6.

30. Khader Y, Al-Zoubi D, Amarin Z, et al. Factors affecting medical students in formulating their speciality preferences in Jordan. BMC Med Educ. 2008;8:32.

31. Ku MC. When does gender matter? Gender differences in speciality choice among physicians. Work Occup. 2011;38(2):221-62.

32. Lefevre JH, Roupret M, Kerneis S, Karila L. Career choices of medical students: a national survey of 1780 students. Med Educ. 2010;44(6):603-12.

33. Mehmood SI, Kumar A, Al-Binali A, Borleffs JC. Speciality preferences: trends and perceptions among Saudi undergraduate medical students. Med Teach. 2012;34(Suppl 1):S51-60.

34. Mwachaka PMM, Mbugua ET. Speciality preferences among medical students in a Kenyan university. PAMJ. 2010;5:18.

35. Parsa S, Aghazadeh A, Nejatisafa AA, et al. Freshmen versus interns' speciality interests. AIM. 2010;13:509-15.

36. van Tongeren-Alers M, van Esch M, Verdonk P, Johansson E, Hamberg K, Lagro-Janssen ALM. Are new medical students' speciality preferences gendered? Related motivational factors at a Dutch medical school. TLM. 2011;23(3):263-8.

37. Gjerberg E. Gender similarities in doctors' preferences-and gender differences in final specialisation. Soc Sci Med. 2002;54(4):591-605.

38. UNESCO. The section for women and gender equality: UNESCO'S Gender Mainstreaming Implementation Framework (GMIF) for 2002-2007. 2003. 
39. Howe A, Ives G. Does community-based experience alter career preference? New evidence from a prospective longitudinal cohort study of undergraduate medical students. Med Educ. 2001;35(4):391-7.

Margret Alers is a researcher conducting her PhD on 'Medical students' gendered preferences regarding their future career and work-life balance'.

Lotte van Leerdam is an MD and in training to become a general practitioner.

Patrick Dielissen is a general practitioner and researcher in the field of gender specific medical education and communication.

Antoine Lagro-Janssen is professor and expert in gender issues in medical education. 